\title{
Determination of trace-level haloacetic acids in drinking water by ion chromatography-inductively coupled plasma mass spectrometry
}

\author{
Yongjian Liu ${ }^{\mathrm{a}}$, Shifen Mou ${ }^{\mathrm{a}, *}$, Dengyun Chen ${ }^{\mathrm{b}}$ \\ ${ }^{a}$ Research Center for Eco-Environmental Sciences, Chinese Academy of Sciences, P.O. Box 2871, Beijing 100085, China \\ ${ }^{\mathrm{b}}$ Agilent Technologies Co. Ltd., Beijing 100085, China
}

Available online 7 February 2004

\begin{abstract}
A new method for the determination of nine haloacetic acids (HAAs) with ion chromatography (IC) coupled to inductively coupled plasma mass spectrometry (ICP-MS) was developed. With the very hydrophilic anion-exchange column and steep gradient of sodium hydroxide, the nine HAAs could be well separated in $15 \mathrm{~min}$. After suppression with an ASRS suppressor that was introduced in between IC and ICP-MS, the background was much decreased, the interference caused by sodium ion present in eluent was removed, and the sensitivities of HAAs were greatly improved. The chlorinated and brominated HAAs could be detected as ${ }^{35} \mathrm{ClO}$ and ${ }^{79} \mathrm{Br}$ without interference of the matrix due to the elemental selective ICP-MS. The detection limits for mono-, di-, trichloroacetic acids were between 15.6 and $23.6 \mu \mathrm{g} / \mathrm{l}$. For the other six bromine-containing HAAs, the detection limits were between 0.34 and $0.99 \mu \mathrm{g} / \mathrm{l}$. With the pretreatment of OnGuard Ag cartridge to remove high concentration of chloride in sample, the developed method could be applied to the determination of HAAs in many drinking water matrices. (C) 2004 Elsevier B.V. All rights reserved.
\end{abstract}

Keywords: Water analysis; Haloacetic acids; Halogenated compounds; Acetic acids

\section{Introduction}

Disinfection with chlorine can effectively control infectious microbial contaminants in drinking water. However, during the disinfection process, chlorine can also react with organic matter that naturally occurs in raw water, producing a variety of chlorine-containing by-products. If there is bromide in raw water, the bromine-containing compounds can be generated, too.

In all the disinfection by-products (DBPs), haloacetic acids (HAAs) is one important kind of DBPs, which accounts for $\sim 13 \%$ of the identifiable post-disinfection halogenated organic matter [1]. There are a total of nine HAAs species containing chlorine: monochloro-, dichloroand trichloroacetic acid (MCAA, DCAA, TCAA, respectively), and bromine: monobromo-, dibromo- and tribromoacetic acid (MBAA, DBAA, TBAA, respectively), and the mixed species bromochloro-, bromodichloro- and dibromochloroacetic acid (BCAA, BDCAA, DBCAA, respectively). Among the nine HAAs, DCAA and TCAA are

\footnotetext{
* Corresponding author. Tel.: +86-10-6284-9182; fax: +86-10-6284-9239.

E-mail address: shifenm@mail.rcees.ac.cn (S. Mou).
}

animal carcinogens [2]. Due to the potential adverse human health effects of these compounds, the US Environmental Protection Agency (EPA) has established, in the first stage of the D/DBPs rule, a maximum contaminant level (MCL) of $60 \mu \mathrm{g} / \mathrm{l}$ for the sum of five HAAs (MCAA, DCAA, TCAA, MBAA, DBAA) [3]. The World Health Organization (WHO) also set MCLs for DCAA $(50 \mu \mathrm{g} / \mathrm{l})$ and TCAA $(100 \mu \mathrm{g} / \mathrm{l})$ in drinking water [4].

Currently, methods used to determine HAAs involve gas chromatography (GC) with electron-capture detection (ECD) [5,6] or with mass spectrometry (MS) [7-9], capillary electrophoresis (CE) [10,11], electrospray ionization mass spectrometry (ESI-MS) [12-15], and ion chromatography (IC) $[16,17]$. For the GC methods, HAAs must be derivatizated and extracted from water samples. However, some of the derivatization reagents are harmful compounds, and the extraction is time-consuming. For the CE methods, the extraction is also needed. In addition, the method is not yet adequately rugged or reliable to meet the demands of trace-level quantitation of HAAs. The ESI-MS based technique is a sensitive and selective method. However, for some samples liquid-liquid extraction may be necessary. This is time consuming and adds cost to the analysis [18]. 
HAAs are moderately strong acids and therefore dissociated nearly completely ( $>99 \%)$ to the haloacetate ions under typical drinking water conditions $(\mathrm{pH}>6)$. IC with conductivity detection can be used for the determination of HAAs in drinking water. However, due to its unselective mode of detection, the quantitation of HAAs could be interfered with by sample matrix [18].

IC-inductively coupled plasma (ICP) MS had been used for the detection of chlorine-containing and brominecontaining compounds such as chlorate and bromate in drinking water due to its element selective detection [19-22]. However, most of them were concentrated on the detection of inorganic bromate, there has been little study on the determination of the organic DBPs-HAAs with IC-ICP-MS.

In this paper, a new method was developed for the rapid determination of nine HAAs with ion chromatography coupled with ICP-MS. With a highly hydrophilic anion-exchange column and gradient of sodium hydroxide, the nine HAAs can be well separated. For the elementspecific detection mode, the nine HAAs can be accurately determined without interference of matrix. Owing to the introduction of an ASRS suppressor, the interference arising from sodium ion present in eluent could be eliminated, and the sensitivities of the HAAs were greatly improved. The method was applied to the analysis of nine HAAs in real drinking water samples.

\section{Experimental}

\subsection{Reagents and materials}

All reagents used were of analytical-reagent grade unless specified. MCAA, DCAA, TCAA, MBAA, DBAA, TBAA, BCAA, BDCAA and DBCAA were all obtained from ChemService (USA). The $100 \mathrm{mmol} / \mathrm{l}$ sodium hydroxide was prepared with $50 \%(\mathrm{w} / \mathrm{w})$ sodium hydroxide solution. All solutions were prepared with deionized water further purified by EASYpure LF system (Barnstead, USA) with a specific resistance of $18.3 \mathrm{M} \Omega \mathrm{cm}$, filtered through $0.2 \mu \mathrm{m}$ membrane filter. The HAAs stock solutions $(1000 \mathrm{mg} / \mathrm{l})$ were prepared by dissolving the corresponding mass of solid compounds in purified water. DCAA stock solution was prepared with $99 \%$ DCAA solution. The stock solutions were stored in refrigerator at $4{ }^{\circ} \mathrm{C}$. They could be stable for at least 2 weeks. Standard solutions were prepared daily by diluting the stock solution prior to use.

\subsection{Ion chromatography}

The separation of nine HAAs was accomplished with an ion chromatography system (Dionex, DX500, Sunnyvale, CA, USA) which consisted of an IonPac AG16 guard column (Dionex, $50 \mathrm{~mm} \times 4 \mathrm{~mm}$ ), an IonPac AS16 separation column (Dionex, $250 \mathrm{~mm} \times 4 \mathrm{~mm}$ ), an anion suppressor (Dionex, ASRS-ULTRA, $4 \mathrm{~mm}$ ) and a $150 \mu \mathrm{l}$ sample loop. The suppressor was run in autosuppression external water mode. Instrumental control was performed with a personal computer and PeakNet 5.11 chromatography work station (Dionex). All tubing in the chromatography path (from the outlet of the pump to the interface of ICP-MS) was polyether ether ketone (PEEK) $(0.005$ in. $(0.125 \mathrm{~mm})$ i.d.). The elution of sample was achieved with sodium hydroxide in gradient. The flow rate of eluent was $1.0 \mathrm{ml} / \mathrm{min}$. The current of the suppressor was set at $300 \mathrm{~mA}$, The flow rate of external water was set at $5.0 \mathrm{ml} / \mathrm{min}$. The determination was performed at room temperature, and all samples were injected in triplicate.

\subsection{ICP-MS}

The Agilent 7500a ICP-MS system (Agilent Technologies, USA) was equipped with a Scott double pass spray chamber, a Fassel-type quartz torch and a PFA micro-flow nebulizer $(100 \mu \mathrm{l} / \mathrm{min})$. The IC eluent was introduced into the ICP-MS nebulizer directly, then ionized and detected. The optimal operating conditions when using the nebulizer were as follows: nebulizer argon flow rate was $0.751 / \mathrm{min}$, make-up argon flow rate was $0.4 \mathrm{l} / \mathrm{min}$; radio frequency (RF) power was $1550 \mathrm{~W}$ (shield torch high sensitivity mode), and the spray chamber temperature was $-5^{\circ} \mathrm{C}$. The time resolved analysis (TRA) mode was used for monitoring of the raw counts at $\mathrm{m} / \mathrm{z} 35,51$, and 79 with integration time of $0.3 \mathrm{~s}$ per $\mathrm{m} / \mathrm{z}$. The independent ICP-MS is optimized for high sensitivity first by $1 \mu \mathrm{g} / \mathrm{l} \mathrm{Bi}$ tuning solution. The sensitivity of 2,500,000 cps/ $(\mu \mathrm{gl})$ for Bi was obtained, which was 100 times higher than normal operation sensitivity. Then, $1 \mathrm{mg} / \mathrm{l}$ $\mathrm{Cl}$ was introduced for tuning. The sampling depth and the carrier gas flow rate were tuned to $4.5 \mathrm{~mm}$ and $0.75 \mathrm{l} / \mathrm{min}$, respectively, to obtain the best sensitivity of ${ }^{35} \mathrm{Cl}$ and ${ }^{35} \mathrm{ClO}$ $(\mathrm{m} / \mathrm{z} 5 \mathrm{51})$. The eluent from IC could be directly introduced to ICP-MS after the suppressor by a peristaltic pump with the constant flow rate of $1.0 \mathrm{ml} / \mathrm{min}$.

\section{Results and discussion}

\subsection{Separation of HAAs}

In the nine HAAs, TBAA is a hydrophobic compound and has strong retention on stationary phase of anion-exchange column. In order to get a quick elution, a hydrophilic column should be used. It was reported that carbon and borate solution would decrease the sensitivity and precision of ICP-MS due to the long aspiration [19,20]. Consequently, IonPac AS16 anion-exchange column was selected for its very hydrophilicity, and a sodium hydroxide eluent was correspondingly used to match the column. On the column, TBAA had a weak retention, and could be quickly eluted with a strong eluent. In addition, the eluent was turned to water when it passed through the suppressor, which led to low background and noise in ICP-MS. It was helpful for the improvement of the sensitivities of the HAAs. 
With the element selective ICP-MS, the nine HAAs can be detected in two separate channels as bromine and chlorine, respectively. For the HAAs containing both bromine and chlorine (BCAA, BDCAA and DBCAA), they had responses in both the two channels. Due to the high sensitivity of bromine in ICP-MS, the responses of bromine were preferred for the mixed HAAs. Since the responses of HAAs in the two channels did not interfere each other, the chlorinated and brominated HAAs did not need to be separated from each other. It just needed to get the separation among the three chlorinated HAAs (MCAA, DCAA and TCAA), and the other six bromine-containing HAAs, respectively.
Considering the good separation of weakly retained MCAA, a sodium hydroxide-water gradient was used with a low concentration of $20 \mathrm{mmol} / \mathrm{l}$ sodium hydroxide at the initial elution, and the concentration was kept for $3 \mathrm{~min}$. In order to accelerate the elution of the strongly retained HAAs, the eluent could be used with a high concentration. At $3.0 \mathrm{~min}$, the concentration of sodium hydroxide was sharply increased to $100 \mathrm{mmol} / \mathrm{l}$ within $0.1 \mathrm{~min}$ and then kept for $9 \mathrm{~min}$. Then, the concentration was turned back to the initial state within $3 \mathrm{~min}$. From Fig. 1 (chromatograms of ICP-MS for chlorine-containing HAAs (a) and bromine-containing HAAs (b)), it could be seen that with the AS16 column and the steep gradient of sodium hydroxide eluent, the nine
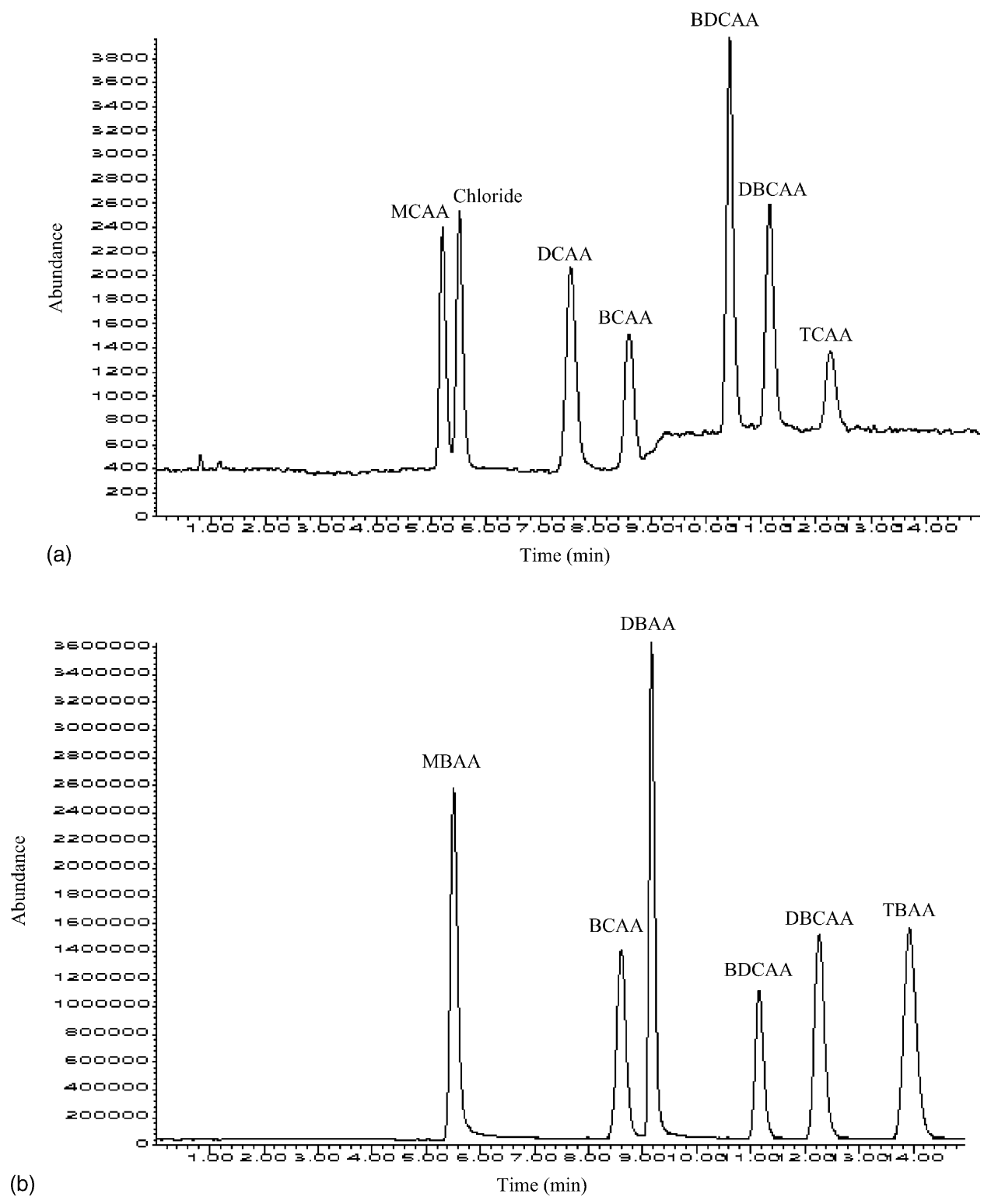

Fig. 1. The chromatogram of standard solution of the nine HAAs. Dionex IonPac AG16 and AS16 columns; ASRS-ULTRA suppressor (4 mm) operated at $300 \mathrm{~mA}$ in autosuppression external water mode; injection volume: $150 \mu \mathrm{l}$; eluent: gradient of $\mathrm{NaOH}, 20 \mathrm{mmol} / 1 \mathrm{for} 3 \mathrm{~min}, 20-100 \mathrm{mmol} / \mathrm{l}$ in $0.1 \mathrm{~min}$, $100 \mathrm{mmol} / 1$ for $9 \mathrm{~min}$ followed by a linear gradient to $20 \mathrm{mmol} / 1$ in $5 \mathrm{~min}$; flow rate: $1.0 \mathrm{ml} / \mathrm{min}$. (a) MCAA $=5 \mathrm{mg} / 1, \mathrm{chloride}=5 \mathrm{mg} / \mathrm{l}, \mathrm{DCAA}=5 \mathrm{mg} / \mathrm{l}$, $\mathrm{BCAA}=5 \mathrm{mg} / \mathrm{l}, \mathrm{BDCAA}=10 \mathrm{mg} / \mathrm{l}, \mathrm{DBCAA}=10 \mathrm{mg} / \mathrm{l}, \mathrm{TCAA}=5 \mathrm{mg} / \mathrm{l}, \mathrm{m} / 2.51$. (b) $\mathrm{MBAA}=10 \mathrm{mg} / \mathrm{l}, \mathrm{BCAA}=5 \mathrm{mg} / \mathrm{l}, \mathrm{DBAA}=8 \mathrm{mg} / \mathrm{l}$, $\mathrm{BDCAA}=10 \mathrm{mg} / \mathrm{l}, \mathrm{DBCAA}=10 \mathrm{mg} / \mathrm{l}$, TBAA $=10 \mathrm{mg} / \mathrm{l}, \mathrm{m} / \mathrm{z} 79$ 
Table 1

The detection limits, linearity, repeatability and spiked recovery of the nine HAAs

\begin{tabular}{|c|c|c|c|c|c|c|c|c|c|}
\hline Analyte & MCAA & MBAA & BCAA & DCAA & DBAA & TCAA & BDCAA & DBCAA & TBAA \\
\hline Standard solution $(\mu \mathrm{g} / \mathrm{l})$ & 250 & 10 & 10 & 250 & 10 & 250 & 10 & 10 & 10 \\
\hline R.S.D. $(n=7, \%)$ & 4.95 & 3.27 & 3.18 & 2.19 & 3.66 & 4.01 & 3.11 & 4.28 & 4.77 \\
\hline Spiked $(\mu \mathrm{g} / 1)$ & 100 & 5 & 5 & 100 & 5 & 100 & 5 & 5 & 5 \\
\hline Recovery $(\%)$ & 92.7 & 96.3 & 95.2 & 94.1 & 103.8 & 92.4 & 93.1 & 92.9 & 91.7 \\
\hline R.S.D. $(n=7, \%)$ & 5.27 & 3.44 & 3.01 & 3.79 & 2.98 & 3.22 & 3.76 & 4.99 & 4.73 \\
\hline Detection limit ${ }^{\mathrm{a}}\left({ }^{35} \mathrm{Cl}, \mu \mathrm{g} / \mathrm{l}\right)$ & 42.6 & & 42.5 & 20.8 & & 47.1 & 67.4 & 127.6 & \\
\hline Detection limit $\left({ }^{35} \mathrm{ClO}, \mu \mathrm{g} / \mathrm{l}\right)$ & 21.2 & & 26.3 & 15.6 & & 23.6 & 35.8 & 77.4 & \\
\hline Detection limit $\left({ }^{79} \mathrm{Br}, \mu \mathrm{g} / \mathrm{l}\right)$ & & 0.45 & 0.34 & & 0.34 & & 0.99 & 0.58 & 0.45 \\
\hline Linear range $(\mu \mathrm{g} / \mathrm{l})$ & $50-500$ & $1-200$ & $1-200$ & $50-500$ & $1-200$ & $50-500$ & $2-200$ & $2-200$ & $1-200$ \\
\hline Correlation coefficient $\left(r^{2}\right)$ & 0.9976 & 0.9981 & 0.9991 & 0.9990 & 0.9985 & 0.9993 & 0.9988 & 0.9987 & 0.9990 \\
\hline
\end{tabular}

a The detection limits for the HAAs were calculated as three times the standard deviation of the blank.

HAAs could be well separated and detected in $15 \mathrm{~min}$. It can save about $30 \mathrm{~min}$ by contrast with the determination of the HAAs with IC by employing the same column and eluent, but a nonselective conductivity detector [23].

\subsection{Detection of HAAs}

In ICP-MS, the detection of chlorine-containing HAAs could be detected as ${ }^{35} \mathrm{Cl}$ and ${ }^{35} \mathrm{ClO}$. For the same sample, the response of ${ }^{35} \mathrm{Cl}$ was much higher than that of ${ }^{35} \mathrm{ClO}$. However, the determination of ${ }^{35} \mathrm{Cl}$ interfered with nitrogen and oxygen, which naturally occur in air. The background and baseline noise of ${ }^{35} \mathrm{Cl}$ were much higher than that of ${ }^{35} \mathrm{ClO}$. For ${ }^{35} \mathrm{ClO}$, though its sensitivity was a little low, the detection was hardly interfered, which resulted in a lower detection limits for the chlorine-containing HAAs than those of ${ }^{35} \mathrm{Cl}$ (Table 1).
The ionization energy of sodium (Na) is much lower than chlorine and bromine. Sodium ion is much easier to be ionized than the two elements in ICP-MS. For the high concentration of sodium ion in the eluent, the ionized sodium gave rise to high background and noise, which led to poor sensitivities of the nine HAAs, especially for chlorine-containing HAAs due to the high ionization energy. In order to improve the sensitivity of the HAAs, an ASRS-suppressor was used to remove the sodium ions by cation exchange. The suppressor was introduced between the separation column and ICP-MS, and run in autosuppression external water mode. The current of the suppressor was set at $300 \mathrm{~mA}$. In the chamber of the suppressor, almost all the sodium ions were exchanged out with hydrogen ion. The eluent was turned to water. The background of the eluent was greatly decreased. The responses and sensitivities of the nine HAAs were much improved. From Table 1, it could

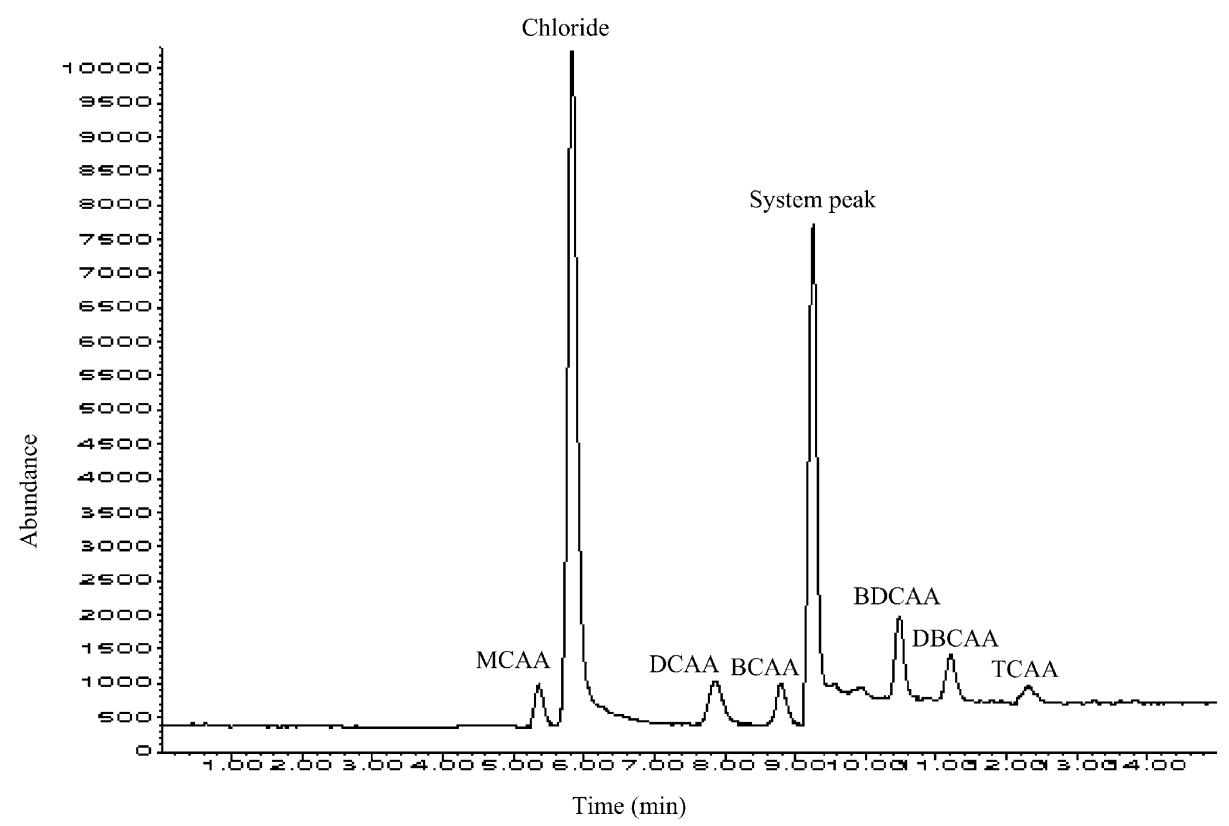

Fig. 2. Chromatogram of chloride and chlorinated HAAs. Dionex IonPac AG16 and AS16 columns; ASRS-ULTRA suppressor (4 mm) operated at $300 \mathrm{~mA}$ in autosuppression external water mode; injection volume: $150 \mu \mathrm{l}$; eluent: gradient of $\mathrm{NaOH}, 20 \mathrm{mmol} / \mathrm{l}$ for $3 \mathrm{~min}, 20-100 \mathrm{mmol} / \mathrm{l}$ in $0.1 \mathrm{~min}, 100 \mathrm{mmol} / \mathrm{l}$ for $9 \mathrm{~min}$ followed by a linear gradient to $20 \mathrm{mmol} / 1$ in $5 \mathrm{~min}$; flow rate: $1.0 \mathrm{ml} / \mathrm{min}$. MCAA $=100 \mu \mathrm{g} / \mathrm{l}$, chloride $=3000 \mu \mathrm{g} / \mathrm{l}, \mathrm{DCAA}=100 \mu \mathrm{g} / \mathrm{l}$, $\mathrm{BCAA}=100 \mu \mathrm{g} / \mathrm{l}, \mathrm{BDCAA}=200 \mu \mathrm{g} / \mathrm{l}, \mathrm{DBCAA}=200 \mu \mathrm{g} / \mathrm{l}, \mathrm{TCAA}=100 \mu \mathrm{g} / \mathrm{l}, \mathrm{m} / z 51$. 
be seen that the detection limits $\left({ }^{35} \mathrm{ClO}\right)$ of MCAA, DCAA and TCAA were decreased to $15.6-23.6 \mu \mathrm{g} / \mathrm{l}$, which were only one-tenth of those obtained without the suppressor. For the other six bromine-containing HAAs, the detection limits $\left({ }^{79} \mathrm{Br}\right)$ were about one third of those obtained without the suppressor. All the detection limits for the brominated HAAs were between 0.34 and $0.99 \mu \mathrm{g} / \mathrm{l}$. It also could be learned from the table that the method was a satisfying one with good precisions and high spiked recoveries.

In DCAA, there have two chlorines, which is two times as many as that in MCAA. In ICP-MS, the response of DCAA should be two times as high as that of MCAA. The detection limit of DCAA should be half of MCAA. However, from Table 1, it could be seen that the detection limits of DCAA was only a little lower than that of MCAA. It was because of the effect of sodium ion in the eluent. In the IC system, the dead time was about $3 \mathrm{~min}$. At $3.0 \mathrm{~min}$, the concentration of sodium hydroxide was changed from 20 to $100 \mathrm{mmol} / \mathrm{l}$ within $0.1 \mathrm{~min}$. The retention time of MCAA was $5.2 \mathrm{~min}$, which indicated that when MCAA was eluted from the column, the concentration of sodium hydroxide in the eluent was still $20 \mathrm{mmol} / \mathrm{l}$. For DCAA, its retention time was about $7.6 \mathrm{~min}$, which indicated that the concentration of sodium hydroxide was increased to $100 \mathrm{mmol} / \mathrm{l}$ when it was eluted. Due to the very high concentration, sodium ions could not be completely removed. The remained sodium ion would be ionized and led to higher noise, background and poorer sensitivity for DCAA than those of MCAA, which could be proved by Fig. 1a, where an increase of background and high baseline noise could be found after the eluting of BCAA. Consequently, the detection limit of DCAA was only a little lower than MCAA. However, if two ASRS suppressors could be connected in series, the sodium ion in the eluent might be totally removed, and the detection for chlorinated and brominated HAAs could be further improved. For the detection limits of TCAA, BCAA, BDCAA, DBAA, DBCAA and TBAA, similar situation occurred.

\subsection{Real sample analysis}

In real drinking water sample, there are a lot of anions such as nitrate and sulphate, etc. In IC with conductivity detection, the anions would interfere with the detection of HAAs. With detection by the element-specific ICP-MS, the high concentrations of nitrate and sulphate did not interfere with the accurate quantitation of the HAAs. However, chloride naturally occurs and its concentration is much higher than that of MCAA. Due to the close retentions of the two compounds on the column, the high concentration of chloride might interfere the quantitation of the little MCAA. From Fig. 2, it could be seen that $100 \mu \mathrm{g} / \mathrm{l}$ MCAA could be accurately detected when the concentration of chloride in the sample was $3 \mathrm{mg} / \mathrm{l}$. However, for most real drinking water samples, the concentration of chloride were much higher than $3 \mathrm{mg} / \mathrm{l}$; the high response of chloride might probably interfere the detection of a trace level of MCAA. For the sake of the exact quantitation of trace level of MCAA present in the sample containing high concentration of chloride, the OnGurad Ag cartridge should be used to remove the large amount of chloride in sample. With one $1.0 \mathrm{ml} \mathrm{Ag}$ cartridge, more than 99.9\% of chloride could be removed when the concentration of chloride was less than $400 \mathrm{mg} / \mathrm{l}$ [24]. In most drinking water samples in China, the concentrations of chloride were less than $100 \mathrm{mg} / \mathrm{l}$, which indicated that the cartridge was available in the pretreatment of the real samples.

In order to test the reliability of the method, simulated experiment was conducted. The synthetic solutions that contained $100,000 \mu \mathrm{g} / \mathrm{l}$ chloride and nine HAAs which were in different concentration levels were treated with the Ag cartridge. The recoveries of the HAAs are listed in Table 2. The results indicated that in the matrices more than $99.92 \%$ chloride could be removed with one $1.0 \mathrm{ml} \mathrm{Ag}$ cartridge. The residual chloride did not interfere with the detection of MCAA. For MCAA, DCAA and TCAA, good recoveries and precisions could always be obtained even their concentrations were near their detection limits when treated with the cartridge. For the bromine-containing HAAs, when their concentrations were all in $5 \mu \mathrm{g} / \mathrm{l}$ level and treated with the cartridge, all the recoveries were above $85 \%$. In addition, with the cartridge, trace level of bromide in real drinking water sample could also be removed, which prevented the potential interference to the bromine-containing HAAs caused from bromide. In addition, phosphate in drinking water could be removed at the same time, which avoided the potential

Table 2

The recoveries of HAAs treated by Ag cartridge with high concentration of chloride

\begin{tabular}{|c|c|c|c|c|c|c|c|c|c|c|}
\hline & $\mathrm{Cl}^{-}$ & MCAA & MBAA & BCAA & DCAA & DBAA & TCAA & BDCAA & DBCAA & TBAA \\
\hline Concentration $(\mu \mathrm{g} / 1)$ & 100,000 & 1000 & 1000 & 1000 & 1000 & 1000 & 1000 & 1000 & 1000 & 1000 \\
\hline Average recovery $(\%, n=5)$ & 0.08 & 97.8 & 98.3 & 103.4 & 98.7 & 104.5 & 99.2 & 98.0 & 103.9 & 105.2 \\
\hline R.S.D. $(\%, n=5)$ & 8.79 & 4.67 & 3.12 & 3.78 & 4.65 & 2.19 & 5.46 & 3.28 & 4.09 & 3.98 \\
\hline Concentration $(\mu \mathrm{g} / \mathrm{l})$ & 100,000 & 100 & 100 & 100 & 100 & 100 & 100 & 100 & 100 & 100 \\
\hline Average recovery $(\%, n=5)$ & 0.09 & 86.7 & 97.9 & 99.6 & 90.1 & 105.8 & 88.1 & 97.7 & 96.1 & 94.3 \\
\hline R.S.D. $(\%, n=5)$ & 6.55 & 12.3 & 3.98 & 4.05 & 10.9 & 3.56 & 10.4 & 5.11 & 3.08 & 3.24 \\
\hline Concentration $(\mu \mathrm{g} / \mathrm{l})$ & 100,000 & & 5 & 5 & & 5 & & 5 & 5 & 5 \\
\hline Average recovery $(\%, n=5)$ & 0.08 & & 90.6 & 87.6 & & 88.8 & & 86.1 & 91.3 & 85.4 \\
\hline R.S.D. $(\%, n=5)$ & 7.89 & & 6.09 & 8.12 & & 6.63 & & 7.03 & 6.06 & 5.89 \\
\hline
\end{tabular}



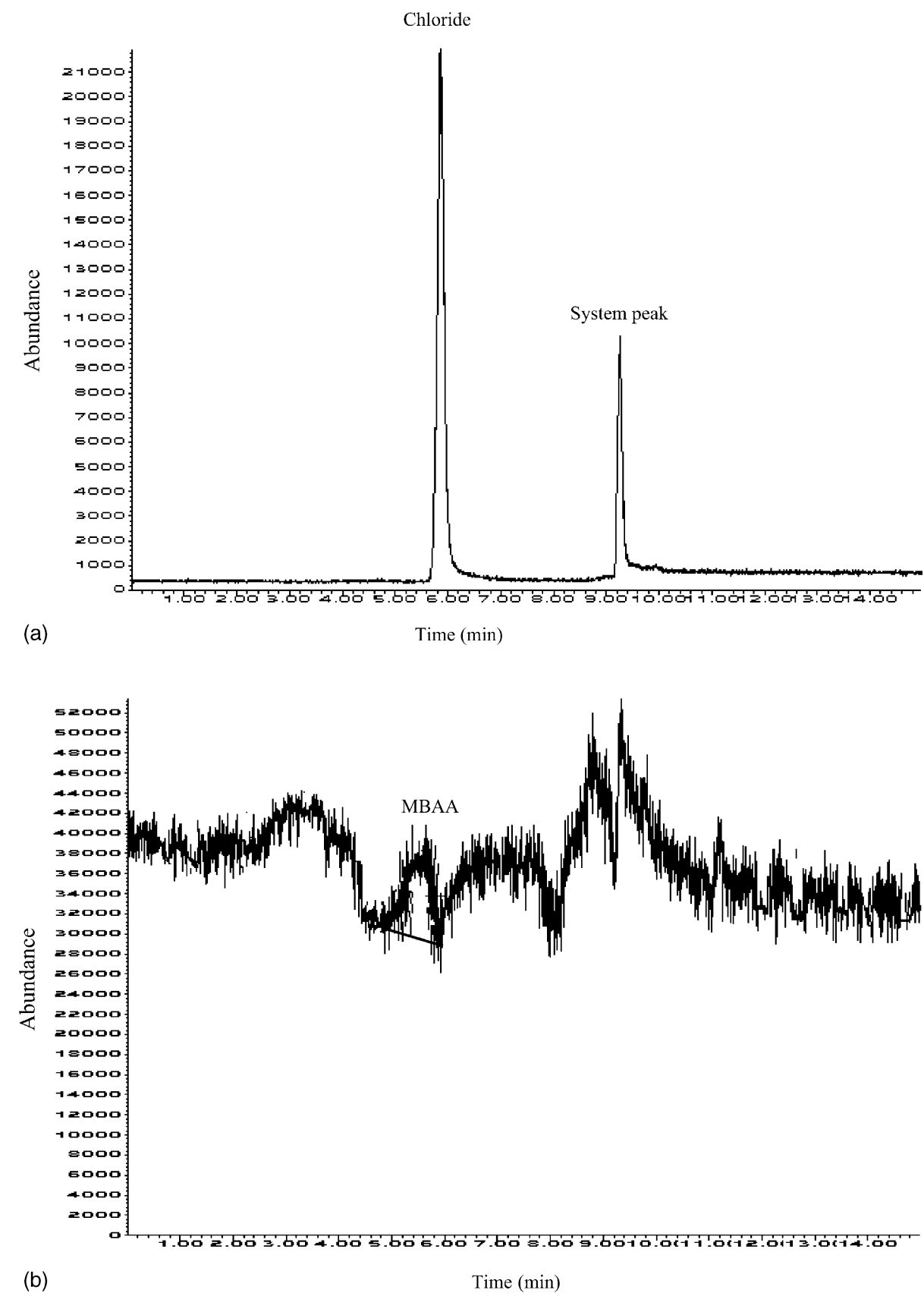

Fig. 3. Chromatogram of HAAs in real drinking water sample. Dionex IonPac AG16 and AS16 columns; ASRS-ULTRA suppressor (4 mm) operated at $300 \mathrm{~mA}$ in autosuppression external water mode; injection volume: $150 \mu \mathrm{l}$; eluent: gradient of $\mathrm{NaOH}, 20 \mathrm{mmol} / \mathrm{l}$ for $3 \mathrm{~min}, 20-100 \mathrm{mmol} / \mathrm{l}$ in $0.1 \mathrm{~min}$, $100 \mathrm{mmol} / \mathrm{l}$ for $9 \mathrm{~min}$ followed by a linear gradient to $20 \mathrm{mmol} / \mathrm{l}$ in $5 \mathrm{~min}$; flow rate: $1.0 \mathrm{ml} / \mathrm{min}$. (a) Chlorinated HAAs, $\mathrm{m} / z$, 51 , (b) brominated HAAs, $m / z 79, \mathrm{MBAA}=5.2 \mu \mathrm{g} / \mathrm{l}$.

interference to ${ }^{79} \mathrm{Br}$ caused by phosphate. From the above results, it can be concluded that the developed method was a reliable one and could be used to the pretreatment and determination of trace level of HAAs in many matrices.

The developed method was used for the analysis of HAAs in Beijing's drinking water samples. The results showed that no chlorine-containing HAAs were detected (Fig. 3a). For brominated acetic acid, only little MBAA was found in three drinking water samples (Fig. 3b). Its average concentration was $5.2 \mu \mathrm{g} / \mathrm{l}$.

\section{Conclusion}

A selective and sensitive technique for the rapid analysis of all nine HAAs containing bromine and chlorine is demonstrated for measuring trace levels in a variety of drinking water matrices. Following IC separation, ICP-MS was used for the detection of organic HAAs. The determination could be accomplished in $15 \mathrm{~min}$. With the introduction of an ASRS suppressor and an OnGuard Ag cartridge, the developed technique became reliable and sensitive, and 
could be used for the analysis of the compounds in many matrices.

\section{References}

[1] H. Weinberg, Anal. Chem. 71 (1999) 801A.

[2] A.M. Richard, E.S. Hunter, Teratology 53 (1996) 352.

[3] US Environmental Protection Agency, Stage 1 disinfectants and disinfection by-products rule, EPA document no. 815-F98-010, GPO, Washington, DC, 1998.

[4] WHO, Revision of the WHO guidelines for drinking water quality, WHO, Geneva, 1991.

[5] Methods for the determination of organic compounds in drinking water, Supplement III, Determination of organic compounds in drinking water by liquid-liquid extraction, derivatization and gas chromatography with electron-capture detection; Method 552.2, EPA/600/R-95/131; EPA, Environmental Monitoring System Laboratory, Cincinnati, OH, 1995.

[6] A.D. Nikolaou, S.K. Golfinopoulos, M.N. Kostopoulou, T.D. Lekas, Water Res. 36 (2002) 1089.

[7] H. Ozawa, J. Chromatogr. 644 (1993) 375.

[8] M.N. Sarrión, F.J. Santos, M.T. Galceran, J. Chromatogr. A 859 (1999) 159.

[9] M.N. Sarrión, F.J. Santos, M.T. Galceran, Anal. Chem. 72 (2000) 4865 .
[10] D. Martínez, F. Borrull, M. Calull, J. Chromatogr. A 835 (1999) 187.

[11] D. Martínez, J. Farré, F. Borrull, M. Calull, J. Ruana, A. Colom, J. Chromatogr. A 808 (1998) 229.

[12] B. Ells, D.A. Barnett, R.W. Purves, R. Guevremont, Anal. Chem. 72 (2000) 4555.

[13] B. Ells, D.A. Barnett, K. Froese, R.W. Purves, S. Hrudey, R. Guevremont, Anal. Chem. 71 (1999) 4747.

[14] S. Hashimoto, A. Otsuki, J. High Resolut. Chromatogr. 21 (1998) 55.

[15] M.L. Magnuson, C.A. Kelty, Anal. Chem. 72 (2000) 2308.

[16] V. Lopez-Avila, Y. Liu, C. Charan, J. AOAC Int. 82 (1999) 689.

[17] C. Sarzanini, M.C. Bruzzoniti, E. Mentasti, J. Chromatogr. A 850 (1999) 197

[18] E.T. Urbansky, J. Environ. Monit. 2 (2000) 285.

[19] M. Pantsar-Kallio, P.K.G. Manninen, Anal. Chim. Acta 360 (1998) 161.

[20] J.T. Creed, C. Brockhoff, Anal. Chem. 71 (1999) 722.

[21] A. Seubert, M. Nowak, Fresenius J. Anal. Chem. 360 (1998) 777.

[22] J.T. Creed, C.A. Brockhoff, T.D. Martin, Determination of bromate in drinking water by ion chromatography inductively coupled plasma-mass spectrometry, EPA Method 321.8, Environmental Monitoring System Laboratory, Cincinnati, OH, 1997.

[23] Y.J. Liu, S.F. Mou, J. Chromatogr. A, in press.

[24] Installation Instruction and Troubleshooting Guide for the OnGuard II Cartridges, Document No. 031688, Revision 03, Dionex, Sunnyvale, CA, 23 August 2001. 